\title{
Increased Drought Risk in South Asia under Warming Climate: Implications of Uncertainty in Potential Evapotranspiration Estimates ${ }^{\mathscr{D}}$
}

\author{
SARAN AADHAR AND Vimal Mishra \\ Civil Engineering, Indian Institute of Technology, Gandhinagar, India
}

(Manuscript received 22 September 2019, in final form 12 March 2020)

\begin{abstract}
Observed and projected changes in potential evapotranspiration (PET) and drought are not well constrained in South Asia. Using five PET estimates [Thornthwaite (PET-TH), Hargreaves-Samani (PET-HS), Penman-Monteith (PET-PM), modified Penman-Monteith (PET-MPM), and energy (PET-EN)] for the observed (1979-2018, from ERA5) and future warming climate, we show that significant warming has occurred in South Asia during 1979-2018. PET changes show considerable uncertainty depending on the method used. For instance, PET-TH has increased significantly while all the other four methods show a decline in PET in the majority of South Asia during the observed period of 1979-2018. The increase in PET-TH is substantially higher than PET-HS, PET-PM, and PET-MPM due to a higher (3-4 times) sensitivity of PET-TH to warming during the observed period. Under the $1.5^{\circ}, 2.0^{\circ}$, and $2.5^{\circ} \mathrm{C}$ warming worlds, global climate models from phase 5 of the Coupled Model Intercomparison Project (CMIP5 GCMs) project increases in PET and drought frequency over the majority of the regions. Drought estimates based on PET-EN and PET-MPM are consistent with soil moisture-based drought estimates and project a substantial increase in the frequency of severe droughts under warming climate in South Asia. In addition, the projected frequency of severe drought based on PET-TH, which is an outlier, is about 5 times higher than PET-EN and PET-MPM. Methods to estimate PET contribute the most in the overall uncertainty of PET and drought projections in South Asia, primarily due to PET-TH. Drought estimates based on PET-TH are not reliable for the observed and projected future climate. Therefore, future drought projections should be either based on PET-EN/PET-MPM or soil moisture.
\end{abstract}

\section{Introduction}

Millions of people in South Asia (Bangladesh, Bhutan, India, Pakistan, Nepal, and Sri Lanka) rely on agriculture for their livelihood. The monsoon (June-September) season precipitation is a lifeline that controls water availability in large parts of the region (Mishra et al. 2012; Roxy et al. 2015). However, the summer monsoon has weakened during the recent decades, which can be attributed to large-scale atmospheric and oceanic variability (Guhathakurta and Rajeevan 2008; Mishra et al. 2016; Sinha et al. 2015). The weakening of the summer monsoon in South Asia resulted in more frequent and longer-lasting droughts (Aadhar and Mishra 2017; Dey et al. 2011; Mishra et al. 2016; Singh et al. 2014).

\footnotetext{
7) Supplemental information related to this paper is available at the Journals Online website: https://doi.org/10.1175/JHM-D-190224.s1.

Corresponding author: Vimal Mishra, vmishra@iitgn.ac.in
}

The difference between precipitation and potential evapotranspiration (PET) is a measure of available water (Swann et al. 2016). Changes in precipitation and PET resulted in an expansion of $10 \%$ in semiarid regions in India during the recent decades (1986-2005) in comparison to the previous decades (1951-70; Ramarao et al. 2019).

Estimation of PET can be a potential source of uncertainty in atmospheric water demands and drought (Trenberth et al. 2014; Yuan and Quiring 2014; Sheffield et al. 2012; Dewes et al. 2017), which can lead to an over or underestimation of drought. Recent studies (Dai 2013; Prudhomme et al. 2014; Liu et al. 2018; Zhao and Dai 2015; Lehner et al. 2017; Touma et al. 2015) showed a large uncertainty in the projection of drought severity. For instance, a few studies (Prudhomme et al. 2014; Liu et al. 2018; Gupta and Jain 2018; Touma et al. 2015) reported an increase in drought intensity and duration by the end of the twenty-first century over South Asia. On the other hand, a decline or no significant change in the drought has also been reported by the end 
of the twenty-first century (Dai 2013; Zhao and Dai 2015) and in $1.5^{\circ}$ and $2.0^{\circ} \mathrm{C}$ warming (Lehner et al. 2017).

Estimates of PET only based on temperature (e.g., Thornthwaite method; Thornthwaite 1948) may result in an overestimation of PET and drought (Trenberth et al. 2014; Yuan and Quiring 2014; Sheffield et al. 2012) in comparison to the other methods. Trenberth et al. (2014) and Yuan and Quiring (2014) argued that the PenmanMonteith method (Penman 1948; Monteith 1965) is reliable for PET estimates. However, Milly and Dunne (2016) and Yang et al. (2019) reported that the PenmanMonteith method overestimates PET in increased global mean $\mathrm{CO}_{2}$ condition (RCP8.5) in the future warming period. Therefore, energy-based and modified PenmanMonteith methods that account for changes in stomatal conductance of vegetation under the increased $\mathrm{CO}_{2}$ emission in the warming climate (Roderick et al. 2015) can be more reliable. Drought projections under the warming climate over South Asia remain under scrutiny due to uncertainty in the methods of PET estimations and variability in different climatic regions (arid to humid).

Notwithstanding the importance of drought in highly populated South Asia, uncertainty in PET estimates for drought assessment in the observed and projected future climate in South Asia is not well quantified. In addition, the sensitivity of PET estimates from different methods under the warming climate is not well quantified. Moreover, since PET is a measure of atmospheric water demand, it can vary in different climate regions (humid or arid). However, the utility of different PET estimates and their variability in climate regions of South Asia remains mostly unexplored. Here, we use five methods [Thornthwaite (PET-TH), Hargreaves-Samani (PET-HS), Penman-Monteith (PET-PM), energy (PET-EN), and modified Penman-Monteith (PET-MPM)] to estimate uncertainty in PET and drought frequency under the observed and projected future warming $\left(1.5^{\circ}, 2.0^{\circ}\right.$, and $2.5^{\circ} \mathrm{C}$ warmer worlds) climate in South Asia. The major questions that we aim to address here are: to what extent do different PET methods differ in the observed and projected climate in the different climatic regions of South Asia? And what are the implications of uncertainty and sensitivity of PET estimates under the warming climate?

\section{Data and methods}

\section{a. Observed data}

Since all the variables to estimate PET are not available from the gauge-based observations, we obtained monthly precipitation, maximum temperature, minimum temperature, wind speed, specific humidity, surface pressure, latent heat flux, sensible heat flux, and total column soil moisture (total column soil depth is about $3 \mathrm{~m}$ ) from the European Centre for MediumRange Weather Forecasts Reanalysis version 5 (ERA5) at $0.25^{\circ}$ to estimate the PET. The drought was identified based on the difference between precipitation $P$ and PET $(P-$ PET) and using soil moisture over South Asia using ERA5 data for the 1979-2018 period. We used observed monthly mean $\mathrm{CO}_{2}$ emission data from NOAA's Mauna Loa Atmospheric Observatory (https://www.esrl.noaa.gov/gmd/ccgg/trends/data.html) to account for the response of stomatal conductance in PET-MPM (Yang et al. 2019) for the observational period of 1979-2018. Previously, ERA5 reanalysis was evaluated for the precipitation, temperature, evapotranspiration, runoff, and soil moisture in India against the observed and other reanalysis datasets during 1980-2018 and it was found that ERA5 reanalysis performs better than the other reanalysis products (Mahto and Mishra 2019).

\section{b. Data from CMIP5 and CESM-LENS}

We obtained data from global climate models (GCMs) that participated in phase 5 of the Coupled Model Intercomparison Project (CMIP5; Taylor et al. 2012) for the historical (1861-2005) and the future (2006-2100) periods for the representative concentration pathway 8.5 (RCP8.5). The RCP8.5 is the high emission scenario that represents an increase of $8.5 \mathrm{~W} \mathrm{~m}^{-2}$ in radiative forcing by the end of the twenty-first century. To consider the worst-case scenario, we only use RCP8.5 in our analysis. Monthly data for precipitation, surface air temperature, wind speed, specific humidity, surface pressure, latent heat flux, sensible heat flux, and total column soil moisture were obtained from CMIP5 GCMs, which were further regridded at $1^{\circ}$ spatial resolution to make the data consistent in terms of spatial resolution across the GCMs. We used data from six CMIP5 GCMs [BNU-ESM, CESM1(CAM5), MIROC-ESM-CHEM, GFDL-ESM2M, MPI-ESM-LR, and NorESM1-M; Table S1 in the online supplemental material] out of eight CMIP5 GCMs [all the required variables are not available for the other two GCMs: BCC_CSM1.1(m) and CMCC-CESM], which were evaluated in Ashfaq et al. (2017) for the summer monsoon dynamics, the onset of monsoon, and seasonal variability in the observed climate. Therefore, we used the six (out of eight) CMIP5 GCMs that performed better than the other GCMs (Ashfaq et al. 2017) over South Asia. Aadhar and Mishra (2019) also showed that the aridity projections based on the multimodel ensemble (more than $30 \mathrm{GCMs}$ ) are not reliable due to the inclusion of GCMs that have less skill to simulate Indian 
Summer Monsoon over South Asia. Additionally, we obtained monthly global mean atmospheric $\mathrm{CO}_{2}$ concentration that was available only for GFDL-ESM2M (for other CMIP5 GCMs, monthly $\mathrm{CO}_{2}$ data were not available) for the historical and future (RCP8.5) periods. The $\mathrm{CO}_{2}$ concentration from GFDL-ESM2M is consistent with the other GCMs' annual mean $\mathrm{CO}_{2}$ concentration (Fig. S1). The detailed description of CMIP5 GCMs can be obtained from Knutti and Sedláček (2012) and Taylor et al. (2012).

In addition to CMIP5 data, we obtained a large ensemble simulation from the Community Earth System Model Large Ensemble Numerical Simulation (CESMLENS) to evaluate the role of internal climate variability in drought projections over South Asia (Kay et al. 2015; Kumar et al. 2016). We used monthly precipitation, surface air temperature, wind speed, specific humidity, surface pressure, latent heat flux, and sensible heat flux for 40 runs of CESM-LENS data for the historical and RCP8.5 to estimate PET and drought over South Asia. CESM-LENS data uses 40 different initial conditions that can be used to understand the role of internal climate variability in drought and PET projections (Kumar et al. 2016).

\section{c. Methods}

To understand the variability of PET and drought in the observed and future $\left(1.5^{\circ}, 2.0^{\circ}\right.$, and $2.5^{\circ} \mathrm{C}$ warming) climate over different climatic regions, we classified South Asia into six climatic zones based on aridity index, which is the ratio of precipitation to PET $(\mathrm{AI}=$ precipitation $/ \mathrm{PET})$ : hyperarid $(\mathrm{AI}<0.05)$, arid $(0.05 \leq \mathrm{AI}<0.2)$, semiarid $(0.2 \leq \mathrm{AI}<0.5)$, dry semihumid $(0.5 \leq \mathrm{AI}<0.65)$, wet semihumid $(0.65 \leq$ $\mathrm{AI}<1.33$ ), and humid $(\mathrm{AI} \geq 1.33)$ regions (Arora 2002; Ponce et al. 2000; Safriel et al. 2005; Middleton and Thomas 1997) (Fig. 1a and Table S2). We find that about $39 \%$ of South Asia falls under arid (hyperarid, arid, and semiarid) while about $60 \%$ area is under humid (dry semihumid, wet semihumid, and humid) region (Table S2).

\section{1) ESTIMATION OF POTENTIAL EVAPOTRANSPIRATION (PET)}

To estimate the uncertainty in drought frequency, we used five different PET methods: energy-based method (Milly and Dunne 2016), Thornthwaite method (Thornthwaite 1948), Hargreaves-Samani method (Hargreaves and Samani 1985), Penman-Monteith method (Monteith 1965; Penman 1948), and modified Penman-Monteith method (Yang et al. 2019). Thornthwaite, HargreavesSamani, and Penman-Monteith methods have been widely used to estimate the PET, and the detailed methodology can be obtained from the previous studies (Milly and Dunne 2016; Trenberth et al. 2014; Yuan and Quiring 2014; McKenney and Rosenberg 1993). However, recent studies reported that the stomatal conductance of vegetation varies with the $\mathrm{CO}_{2}$ concentration and vapor pressure deficit (VPD; Novick et al. 2016; Yang et al. 2019; Roderick et al. 2015; Milly and Dunne 2016), which in turn affects PET. We, therefore, used two additional methods: energy (PETEN), and modified Penman-Monteith (PET-MPM) methods.

We estimated PET-EN using latent and sensible heat fluxes as described in Milly and Dunne (2016). Milly and Dunne (2016) reported that PET estimated using the Penman-Monteith method overestimates atmospheric water demand due to the neglect of stomatal conductance under the warming climate. Milly and Dunne (2016) estimated PET-EN using an energy budget as

$$
\mathrm{PET}=0.8\left(R_{n}-G\right),
$$

where $R_{n}$ and $G$ are net radiation at the surface and ground heat flux. Here $R_{n}-G$ can be estimated using the energy balance as $L_{v} E+H$, where $L_{v} E$ is latent flux, and $H$ is sensible heat flux. Milly and Dunne (2016) assumed that $80 \%$ of the total available energy converts into latent flux.

Yang et al. (2019) used a linear relationship between the change in global mean atmospheric $\mathrm{CO}_{2}$ concentration and change in surface resistance $r_{s}$ (the resistance of vapor flow through stomata openings) and incorporated the role of $\mathrm{CO}_{2}$ concentration in the PET-MPM estimation by changing surface resistance $r_{s}$ as

$$
\operatorname{PET}=\frac{0.408 \Delta\left(R_{n}-G\right)+\gamma \frac{900}{T+273} u D}{\Delta+\gamma\left[1+u\left\{0.34+2.4 \times 10^{-4}\left(\left[\mathrm{CO}_{2}\right]-300\right)\right\}\right]},
$$

where $R_{n}$ is net radiation at the surface, $G$ is ground heat flux, $\Delta$ is the slope of the vapor pressure curve, $u$ is wind speed, $D$ is vapor pressure deficit, and $\gamma$ is the psychometric constant.

\section{2) Drought INDices}

We used the standardized precipitation evapotranspiration index (SPEI; drought index; Vicente-Serrano et al. 2010) using the log-logistic distribution to estimate the frequency and area under severe droughts in South Asia. Here, we used a standardized value less than -1.2 to identify the severe drought as in Svoboda et al. (2002). Severe droughts can have implications on agriculture and 


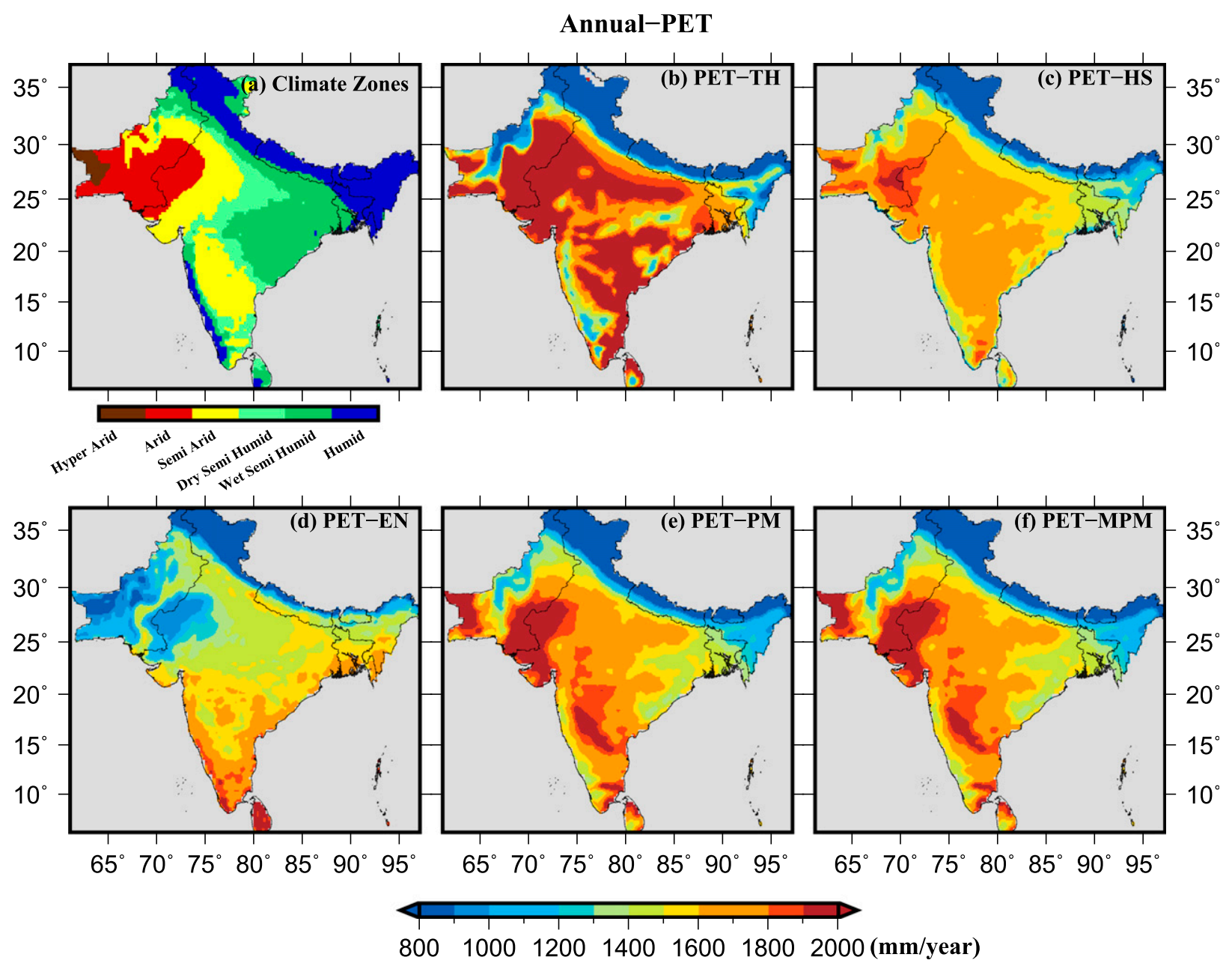

FIG. 1. Climate zones and spatial variation of annual mean PET over South Asia. (a) Different climatic zones in South Asia. Mean annual PET estimated using the (b) Thornthwaite method (PET-TH), (c) Hargreaves-Samani method (PET-HS), (d) energy method (PET-EN), (e) Penman-Monteith method (PET-PM), and (f) modified Penman-Monteith method (PET-MPM) during the period 19792018 using ERA5 reanalysis data.

water resources variability (Mishra et al. 2016). SPEI has been widely evaluated against the other drought indices in different regions (Vicente-Serrano et al. 2010; Rhee and Cho 2016; Gupta and Jain 2018; Kumar et al. 2013). Unlike the precipitation based drought index, SPEI has the advantage of considering the difference between precipitation $P$ and PET $(P-$ PET) to estimate available water for drought identification (Vicente-Serrano et al. 2010). We considered a 12-month time scale to reflect annual drought condition and estimated 12-month SPEI at the end of December for all the five PET methods for observations and each GCM. In addition to SPEI, we used the standardized soil moisture index (SSI; Hao and Aghakouchak 2013) based on total column soil moisture from GCMs for the future climate and ERA5 for the observed period (1979-2018). SSI provides an estimate of soil-centric available water. Therefore, we used both
SPEI and SSI indices for our drought assessment (Swann et al. 2016).

SSI is an agricultural drought index, which may take time to translate meteorological drought (SPEI) into agriculture drought (SSI) due to the high soil moisture persistence (Mishra et al. 2018). To estimate the time scale of SSI that best corresponds to the 12-month SPEI that reflects the annual drought condition, we estimated the correlation between 12-month SPEI and SSI at different time scales (1-12 months). We find that 6-month SSI at the end of December correlates well with 12-month SPEI at the end of December (Table S3). A 6-month SSI at the end of December represents the standardized anomaly of six months accumulated soil moisture from July to December. Then, 12-month SPEI (12-month) and 6-month SSI were estimated for each GCMs using 1971-2000 as the reference climate. 


\section{3) ESTIMATION OF DROUGHT FREQUENCY UNDER A WARMING CLIMATE}

To avoid the severe impact of changing climate, the Paris Agreement under the United Nations Framework Convention on Climate Change aims to hold the global mean temperature below $2^{\circ} \mathrm{C}$ and more ambitiously pursue efforts to limit below $1.5^{\circ} \mathrm{C}$ from the preindustrial level by the end of the twenty-first century (King et al. 2017). However, holding the global mean temperature rise below $2.0^{\circ} \mathrm{C}$ from the preindustrial level is highly unlikely (Raftery et al. 2017). Raftery et al. (2017) found that the likely range of global mean temperature rise is $2.0^{\circ}-4.9^{\circ} \mathrm{C}$ by the end of the twenty-first century, and there is only $5 \%$ chance that global mean temperature rise will be less than $2.0^{\circ} \mathrm{C}$ as targeted in the Paris Agreement. We, therefore, considered three $\left(1.5^{\circ}, 2.0^{\circ}\right.$, and $2.5^{\circ} \mathrm{C}$ ) warming climate conditions to analyze the projected changes in the frequency of severe droughts in South Asia in the changing climate. For $1.5^{\circ}, 2.0^{\circ}$, and $2.5^{\circ} \mathrm{C}$ warming worlds, we used the method described in King et al. (2017) to identify decades in each GCMs that represent $1.5^{\circ}, 2.0^{\circ}$, and $2.5^{\circ} \mathrm{C}$ warming from the preindustrial level (1861-1900). The change in global mean temperature was estimated against the preindustrial period to find the decades of $1.5^{\circ}, 2.0^{\circ}$, and $2.5^{\circ} \mathrm{C}$ warming for each GCM (Fig. S2). King et al. (2017) defined the decades in the $1.5^{\circ}$ and $2.0^{\circ} \mathrm{C}$ world when the decadal global mean temperature is in the range of $1.3^{\circ}-1.7^{\circ} \mathrm{C}$ and $1.8^{\circ}-2.2^{\circ} \mathrm{C}$ above the preindustrial period, respectively. Additionally, we considered the decades for the $2.5^{\circ} \mathrm{C}$ world when the decadal global mean temperature rise is between $2.3^{\circ}$ and $2.7^{\circ} \mathrm{C}$ against the preindustrial period.

Further, we evaluated the changes in the frequency of severe droughts (SPEI and SSI less than -1.2) under the $1.5^{\circ}, 2.0^{\circ}$, and $2.5^{\circ} \mathrm{C}$ warming worlds with respect to the reference climate (1971-2000) in each of the six CMIP5 GCMs. The changes in the drought frequency $(\Delta D F)$ are defined as

$$
\mathrm{DF}(\text { per decade })=\mathrm{DF}_{\text {warm }}-\mathrm{DF}_{\text {ref }},
$$

where $\mathrm{DF}_{\text {warm }}$ is the number of severe droughts (SPEI or SSI <-1.2) per decade in the warming climate $\left(1.5^{\circ}\right.$ or $2.0^{\circ}$ or $\left.2.5^{\circ} \mathrm{C}\right)$, and $\mathrm{DF}_{\text {ref }}$ is the number of severe droughts per decade during the reference climate 1971-2000.

Changes in PET, precipitation, and temperature in the $1.5^{\circ}, 2.0^{\circ}$, and $2.5^{\circ} \mathrm{C}$ warming worlds were estimated against the reference climate of 1971-2000. Further, uncertainty in the projected changes in the PET, drought frequency due to the PET estimation methods, models (GCMs), and their interaction in the $1.5^{\circ}, 2.0^{\circ}$, and $2.5^{\circ} \mathrm{C}$ warming worlds was estimated using the analysis of variance (ANOVA) method (Armstrong et al. 2000; Vetter et al. 2015; Mishra et al. 2017). We used a threeway ANOVA (effect of methods, effect of models, and effect of their interaction) to partition the variance into the source of the contribution. We estimated the total sum of squares due to all effects (total sum of squares), the sum of squares due to individual main effects (methods and models), and sum of squares due to their interaction using ANOVA and estimated the contribution from different factors as described in Vetter et al. (2015). More details about the ANOVA method is provided in section $\mathrm{S} 1$ in the online supplemental material.

For the observational period (1979-2018), we estimated the sensitivity (change in PET to a $1^{\circ} \mathrm{C}$ rise in the mean air temperature) of PET against the mean air temperature for each grid. Change in PET per $1^{\circ} \mathrm{C}$ rise in temperature is estimated using the regression between change in PET and temperature (Vano et al. 2012). We constructed the regression equation (in the form of $d \mathrm{PET} / \mathrm{PET}=\alpha d T / T$ ) for each PET method and estimated sensitivity parameter $\alpha$ using the regression. More details on sensitivity can be obtained from Vano et al. (2012) and Mishra et al. (2017). Changes (trend slope multiplied by the number of years) in the observed climate (1979-2018) were estimated using the nonparametric Mann-Kendall test (Mann 1945; Kendall 1975) and Sen's slope test (Sen 1968). We estimated the magnitude of the trend in annual time series using Sen's slope method (Sen 1968) and calculated the changes by multiplying by the number of years in the time series (trend slope multiplied by the number of years). The Mann-Kendall test has been widely used for assessment of changes in hydroclimatic data, and further details can be obtained from Yue and Wang (2002).

\section{Results}

\section{a. Observed PET and drought (1979-2018)}

\section{1) UNCERTAINTY AND SENSITIVITY OF PET IN THE OBSERVED CLIMATE (1979-2018)}

We find a large variation in PET estimated using the five PET methods in different climate zones during 1979-2018 (Fig. 1, Table S4). For instance, PET-EN is the lowest for hyperarid and highest for the semihumid regions in comparison to the other four methods. However, higher uncertainty in the change in the PET is mainly due to the PET-TH, which shows a significantly different and higher rise in PET in comparison to the other PET methods (PET-EN, PET-HS, PET-PM, and PET-MPM) during the observed period of 1979-2018 (Fig. 2, Fig. S3, Table S5). For instance, an increase in PET-TH in hyperarid 

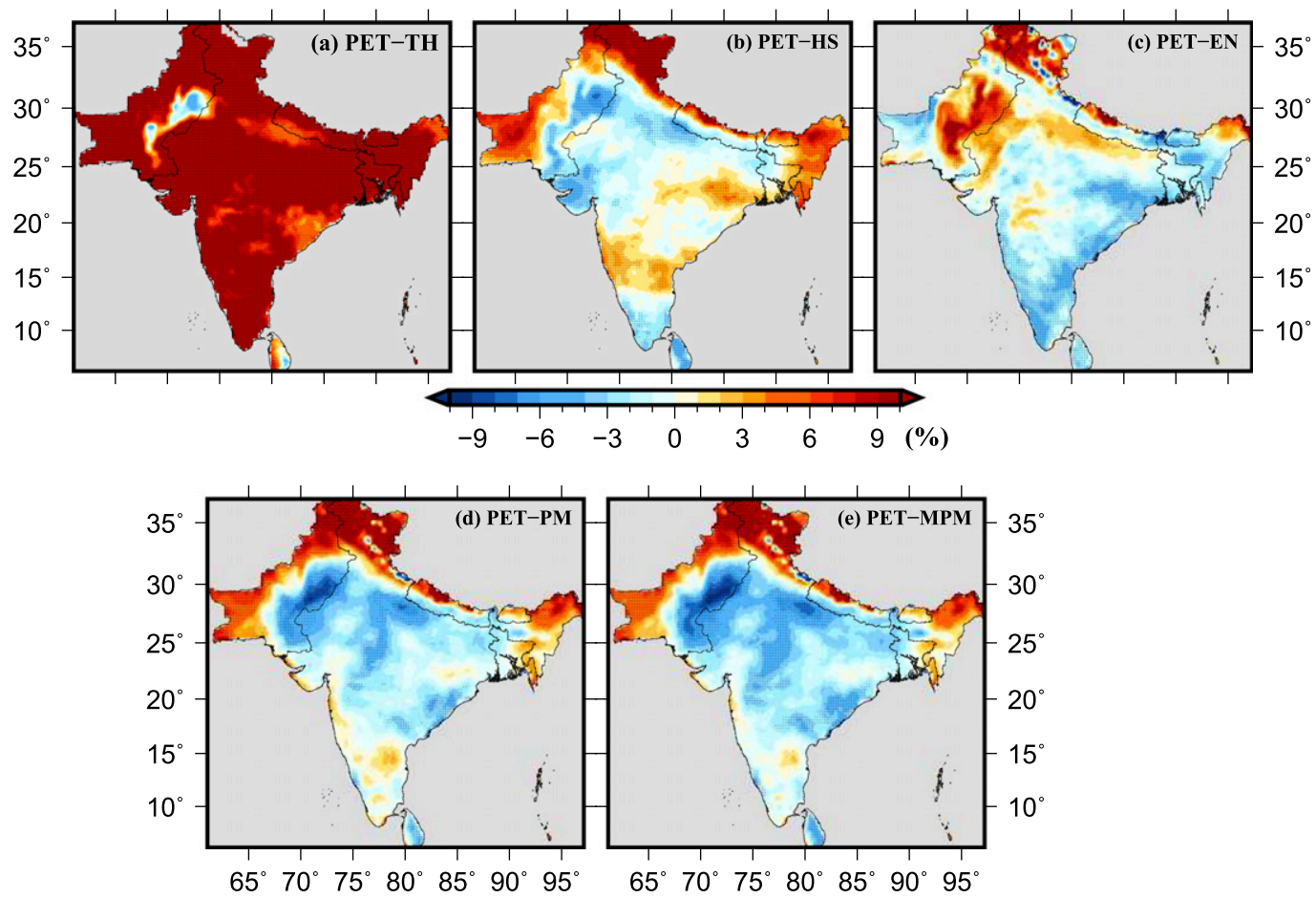

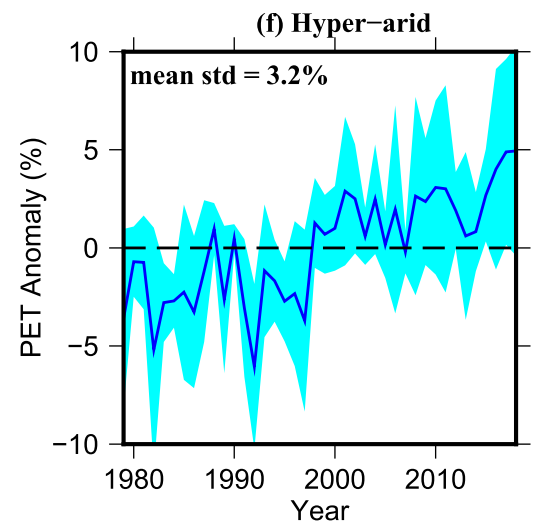

(i) Dry semi-humid

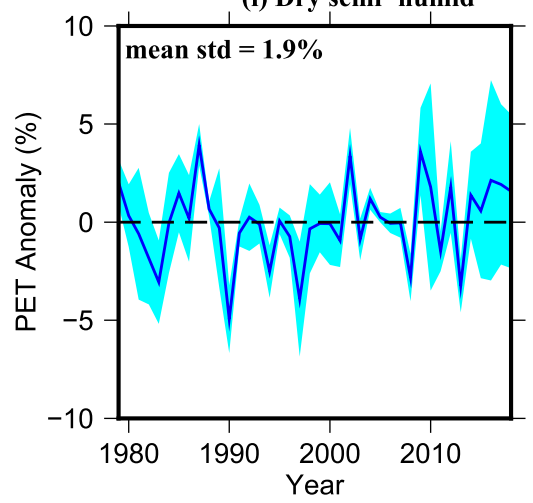

(g) Arid

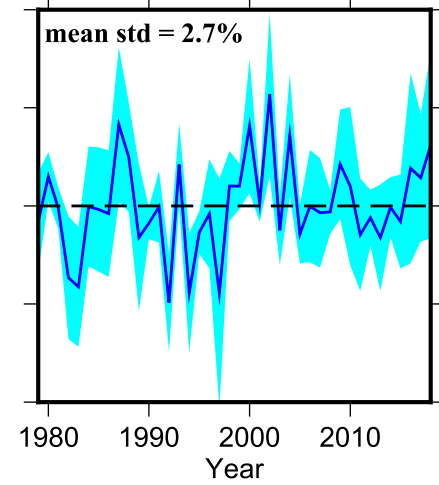

(j) Wet semi-humid

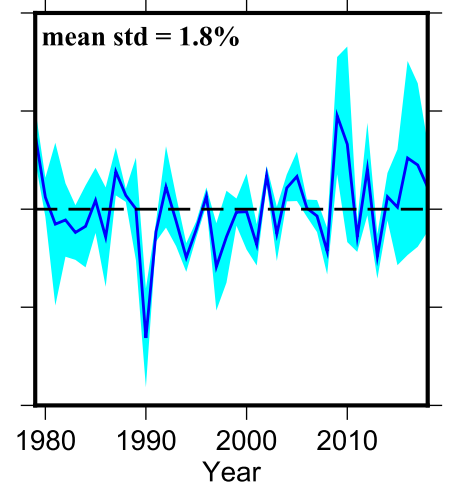

(h) Semi-arid

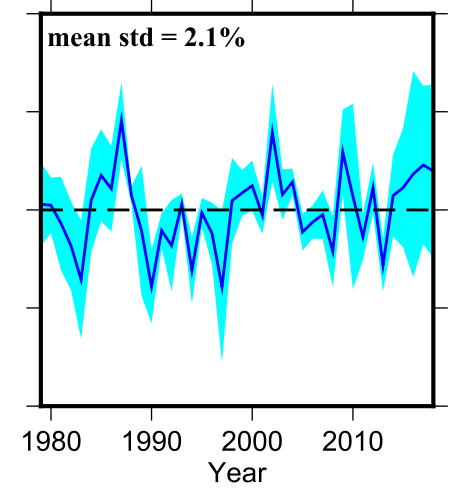

(k) Humid

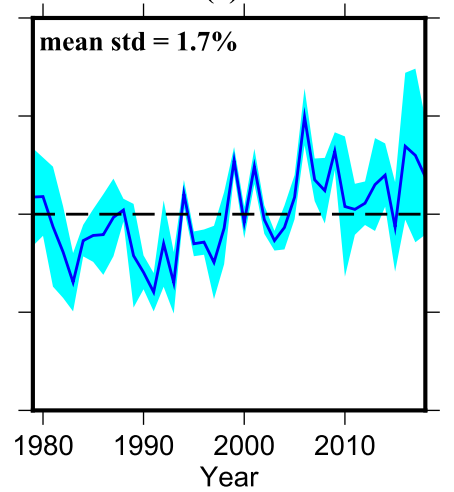

FIG. 2. Changes in annual potential evapotranspiration (PET; \%) over South Asia and in different climatic regions. Changes (\%) in annual (a) PET-TH, (b) PET-HS, (c) PET-EN, (d) PET-PM, and (e) PET-MPM during the period 1979-2018. Changes (\%) in anomaly (\%) in annual PET-EN, PET-MPM, PET-PM, PET-HS, and PET-TH in (f) hyperarid, (g) arid, (h) semiarid, (i) dry semihumid, (j) wet semihumid, and (k) humid regions for 1979-2018 period estimated using ERA5 data. The shaded areas in (f)-(k) show the uncertainty ( \pm 1 standard deviation) in the PET anomaly (\%) due to the five PET methods. 
(a) Change in Net Radiation (\%)

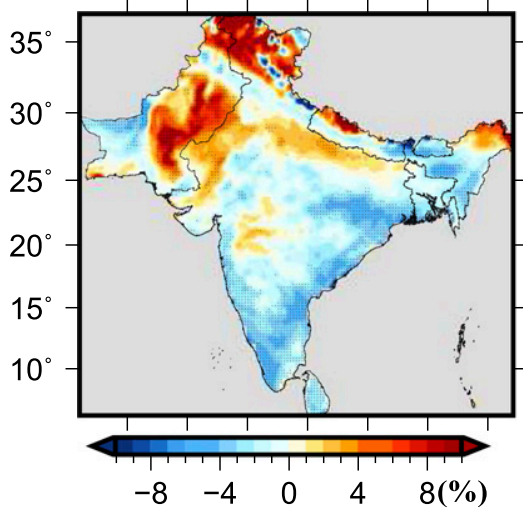

(b) Change in Mean Temperature $\left({ }^{\circ} \mathrm{C}\right)$

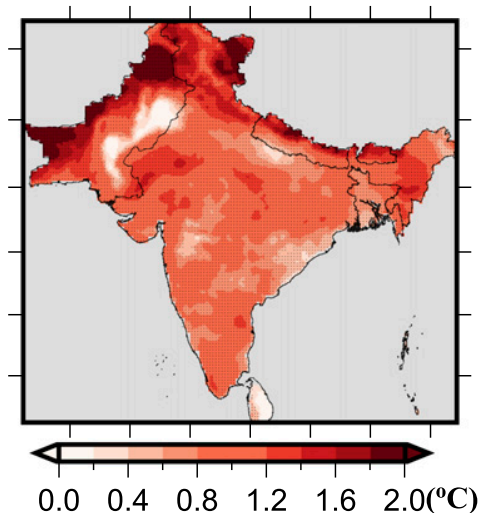

(c) Change in Diurnal Range Temperature (DTR, $\left.{ }^{\circ} \mathrm{C}\right)$

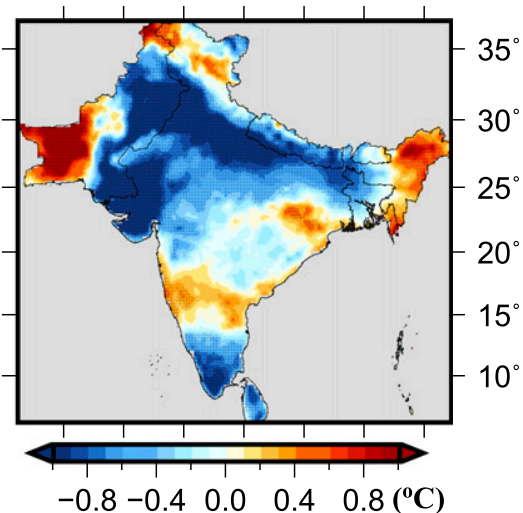

(d) Change in Wind speed $(\%)$

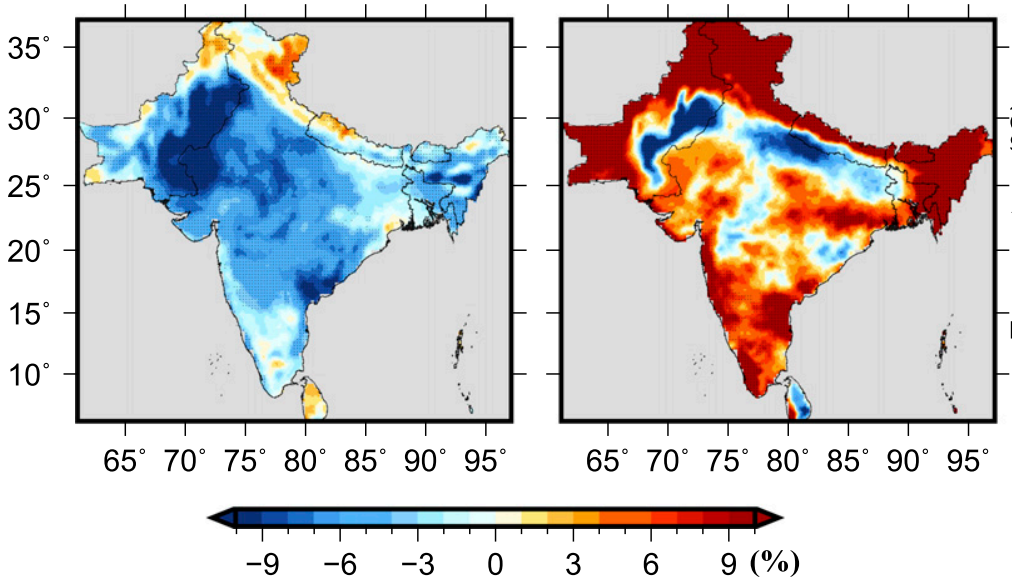

(e) Change in Vapor Pressure Deficit (\%)

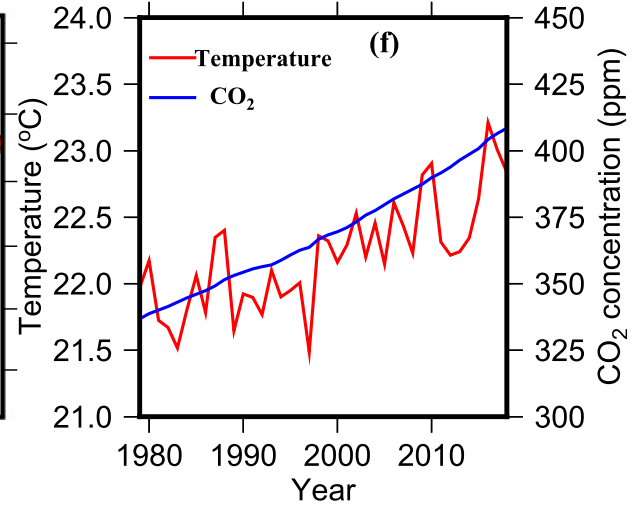

FIG. 3. Changes (\%) in annual mean (a) net radiation, (b) temperature, (c) diurnal temperature range (DTR), (d) wind speed, and (e) vapor pressure deficit during the period 1979-2018 over South Asia. (f) Area-averaged mean temperature $\left({ }^{\circ} \mathrm{C}\right)$ and atmospheric $\mathrm{CO}_{2}$ concentration (ppm) for the period 1979-2018.

and humid regions (change: $21 \%$ and $12.73 \%$ ) are about more than 4 times higher than the other PET methods (PET-PM, PET-MPM, and PET-HS) (Table S5). In the semihumid, arid, and semiarid regions, PET-TH has increased while the other PET methods show a decline during the observed period (Table S5).

PET-TH is relatively lower than the other PET estimates for negative temperature anomalies while higher (in comparison to PET-PM and PET-HS) for positive temperature anomalies (Fig. S3). PET-EN, PET-HS, PET-PM, and PET-MPM show similar changes in PET in all the regions of South Asia during 1979-2018 (Fig. S3). Our results show that PET has increased significantly in the northwestern part of South Asia in all the PET methods during 1979-2018 (Fig. 2). However, except PET-TH, the other methods show a decline in PET in the majority of South Asia. Our results are consistent with the previous studies (Jaswal et al. 2008; Bandyopadhyay et al. 2009; Chattopadhyay and Hulme 1997) that reported a decline in pan evaporation during the observed period (1971-2000). We also compare the PET-MPM and PETPM method to identify the differences in these methods during the observed period (Fig. S4). Due to the increase in the global mean $\mathrm{CO}_{2}$ concentration during the observed period, PET-PM is higher than PET-MPM during 1979-2018 (Fig. S4). However, spatial variation in annual mean PET-PM and PET-MPM are comparable (Fig. 1). Overall, we find that uncertainty ( \pm 1 standard deviation) due to different PET estimates is higher in the hyperarid, arid, and semiarid regions in comparison to the subhumid and humid regions of South Asia (Fig. 2, Table S5).

Next, we analyzed the changes in temperature, wind, vapor pressure deficit, and net radiation from ERA5 during the period 1979-2018 over South Asia to diagnose the causes of a decline in PET in South Asia under the observed climate (Fig. 3). To do so, we quantified the variance of PET explained by the individual climatic 
variables (Figs. S5 and S6). Net radiation has declined in the majority of South Asia during 1979-2018 (Fig. 3a). A significant $(p$ value $<0.05)$ warming in annual mean temperature occurred across South Asia with more rapid warming $\left(\sim 1.75^{\circ} \mathrm{C}\right)$ in the western part of South Asia during 1979-2018 (Fig. 3b). The annual mean temperature has increased significantly $(p$ value $<0.05$ ) in all the climatic regions with the least rise in semihumid (change: $+0.97^{\circ} \mathrm{C}$ ) while most warming occurred in the hyperarid (change: $+1.93^{\circ} \mathrm{C}$ ) regions (Table S5). Annual mean minimum temperature (Tmin) has increased more rapidly in comparison to annual mean maximum temperature (Tmax; Fig. S7), which results in a decline in the diurnal temperature range (DTR) in the majority regions (primarily located in the northern) of South Asia (Fig. 3c). DTR has decreased significantly in the semiarid, dry semihumid, and wet semihumid regions (change: $-0.33^{\circ} \mathrm{C}$ ) while it has increased significantly in the hyperarid region (change: $+1^{\circ} \mathrm{C}$; Table S5). Our results show that wind speed has decreased over the large part of South Asia (Fig. 3d) during the period 1979-2018, which is consistent with the previously reported studies (Vautard et al. 2010). Vapor pressure deficit has increased significantly over the large part of South Asia and decreased over the central regions of South Asia during 1979-2018 (Fig. 3e). The decreased in VPD over the Gangetic Plain and Indus basin can be associated with intensive irrigation in the region (Ray et al. 2002). We find that air temperature and $\mathrm{CO}_{2}$ concentration have increased considerably during the observed record of 1979-2018 (Fig. 3f). Overall, we find that the climatic variables that derive PET have substantially changed during the observed record in South Asia.

More than $95 \%$ of the total variance in PET-EN and PET-TH is explained by net radiation and mean temperature, respectively (Fig. S5). Therefore, the decrease in the PET-EN is associated with a decrease in the net radiation, while an increase in PET-TH is associated with warming. Latent heat and sensible heat fluxes explain the relatively smaller variance of PET-EN than net radiation (Fig. S5). Diurnal temperature range (DTR) and mean temperature explain more than $90 \%$ of the total variance in PET-HS while DTR being the major contributor (Fig. S5). Therefore, decreased DTR in the majority of South Asia can be associated with a decrease in the PET-HS. Net radiation, mean temperature, wind, and VPD together explain more than $95 \%$ of the total variance in PET-PM and PET-MPM during 1979-2018 while VPD being the major contributor (Fig. S6). Therefore, a significant decrease in the PET-PM and PET-MPM are mainly due to the decrease in the VPD (central region), net radiation, and wind speed.
A significant warming has occurred over South Asia during the observed period (1979-2018), which is likely to continue in the future. To understand the coupling between temperature and PET, we estimated the correlation between PET and temperature anomaly during 1979-2018 in each climatic zone (Table S6). A strong relationship (correlation $>0.9$ ) between annual mean temperature and PET-TH was observed in all the climatic regions (Table S6). On the other hand, PET-EN, PET-HS, PET-PM, and PET-MPM are relatively less strongly (correlation $\sim 0.4-0.6$ ) correlated with annual mean temperature, which indicates that the temperature does not solely control PET. For instance, PET-EN does not show a strong linkage with mean annual temperature rather it is driven by net radiation. We estimated the sensitivity of PET to mean annual temperature (Fig. 4, Table S7) using simple linear regression by applying the method described in Vano et al. (2012). As expected, our results show that PET-TH is more sensitive to temperature compared to PET-EN, PET-HS, PET-PM, and PET-MPM (Fig. 4, Table S7). For instance, PETTH increases between $9 \%$ and $13 \%$ in response to a $1{ }^{\circ} \mathrm{C}$ rise in mean annual temperature. The sensitivity of PET-HS, PET-PM, and PET-MPM ranges between $2.0 \%$ and $6.0 \%$ (Table S7) while PET-EN shows negative sensitivity to temperature except in the northern and eastern parts of South Asia. Overall, PET-TH shows substantially higher sensitivity than the other PET estimates for all the climate zones in South Asia. PET-EN shows the least sensitivity to warming in all the regions in South Asia during 1979-2018. Moreover, as explained before only PET-TH is largely associated with temperature, which explains more than $95 \%$ of the total variance (Fig. S5). Since PET-HS, PET-PM, and PET-MPM are more strongly associated with the other variables (DTR, VPD, net radiation, and wind), projected future changes in the PET estimates will not be solely governed by air temperature (Figs. S5 and S6). Therefore, PET based on PET-EN, PET-HS, PET-PM, and PET-MPM show a decline in the observed period with increased temperature.

\section{2) DROUGHT ESTIMATES USING DIFFERENT PET METHODS DURING 1979-2018}

The frequency and area under severe drought were estimated during 1979-2018 using 12-month SPEI based on PET-TH, PET-HS, PET-EN, PET-PM, and PETMPM (Fig. S8). We compared the frequency and area under drought based on 12-month SPEI and 6-month SSI (Fig. S8). We did so to identify the PET method that provides similar estimates based on soil moisture (SSI). Similar to the PET anomaly, the area under severe drought shows a high uncertainty for the hyperarid and 

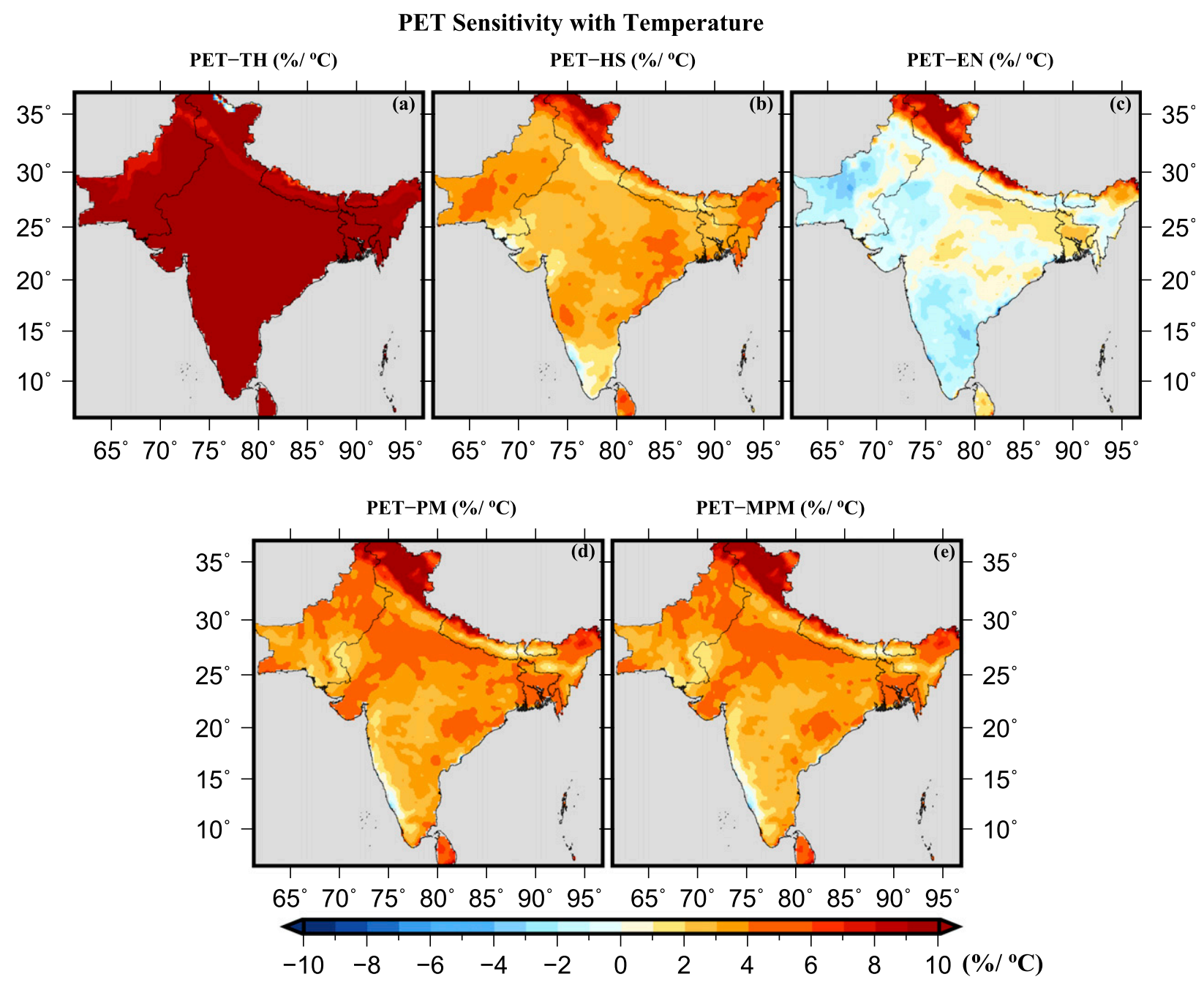

FIG. 4. Sensitivity of PET against temperature over South Asia. Sensitivity in annual mean (a) PET-TH, (b) PET-HS, (c) PET-EN, (d) PET-PM, and (e) PET-MPM against temperature during the period 1979-2018.

arid regions and less uncertainty for the humid regions of South Asia (Figs. S8a-f, Table S8). The frequency and area under drought based on PET-TH were smaller during the pre-1998 period in comparison to SSI and the other four methods (Fig. S9, Table S8). In contrast, the frequency and area under drought based on PET-TH are higher (than SSI and the other PET methods) during the post-1998 period (Figs. S8 and S9, Table S8). This under and overestimation in the drought frequency and area under drought based on PET-TH can be attributed to its higher sensitivity to temperature during the observed climate. Moreover, we compared the spatial coverage of SPEI based drought estimates against the agricultural drought (SSI and NDVI anomaly) for few drought events (1982, 2002, and 2015). Drought coverage based on SPEI is comparable with SSI and NDVI over the majority of regions for most of the PET methods (Figs. S10 and S11). However, drought extent based on PET-TH is underestimated in 1982 and overestimated in 2002 and 2015 compared to other PET based drought estimates (Figs. S10 and S11). This under and overestimation in PET-TH based drought is largely due to anomalous temperature. For instance, if temperature anomaly is negative (e.g., 1982) PET-TH underestimates drought while it overestimates drought extent during the positive temperature anomaly (e.g., 2002 and 2015).

Most of the PET-based estimates show a higher frequency of drought in the post-1998 period in comparison to that estimated based on soil moisture (e.g., SSI) in the majority of the climate zones in South Asia. The correlation between the areal extent estimated using 12-month SPEI and 6-month SSI (Table S9) show a stronger relationship between SSI and SPEI-EN/SPEI-MPM. 
On the other hand, SSI is poorly correlated with SPEI$\mathrm{TH}$ indicating the PET-TH is not an appropriate measure of soil-centric drought while PET-EN and PET-MPM are more suitable methods for drought estimates in South Asia. However, all the PET-based drought estimates show a large difference (weak correlation) against SSI based estimates for hyperarid, arid, and humid regions (Table S9). Therefore, our results show that for extreme dry (arid), PET based estimates of drought can lead to large uncertainty in comparison to soil moisture based drought estimates during the observed climate.

PET-EN is an energy-based method, which is highly associated with net radiation. Net radiation shows a negative correlation with temperature over the western and southern parts of South Asia and a positive correlation in central and eastern South Asia (Fig. S12). Moreover, Latent heat flux is also negatively correlated with temperature over the majority of regions of South Asia, which makes PET-EN less or negatively sensitive to temperature (Fig. S12). On the other hand, variation in PET-HS is mainly explained by the diurnal temperature range (Fig. S5), which can be used for estimation for radiation and humidity (Valiantzas 2018; Hargreaves and Samani 1985). PET-PM and PET-MPM are based on the energy budget and mainly associated with VPD, wind, and net radiation (Fig. S6). Therefore, the sensitivity of PET-EN, PET-HS, PET-PM, and PET-MPM methods to temperature is smaller than PET-TH. Since we aim to estimate PET and drought frequency under the warming climate in South Asia, we limit our analysis on the sensitivity of PET to temperature. However, previous studies evaluated the sensitivity of PET to the other parameters (Scheff and Frierson 2014; Fu and Feng 2014; Roderick et al. 2015). Strong drying trend using the PET-TH based drought indices in the previous studies (Gupta and Jain 2018; Yuan and Quiring 2014; Sheffield et al. 2012) can be an overestimate. Moreover, even the advanced methods of PET estimates can produce uncertainty for arid regions in comparison to the estimates based on soil moisture during the observed climate (1979-2018).

\section{b. Projected changes in PET and drought frequency}

\section{1) Projected changes in PeT}

Next, we estimated the change in PET under different warming levels $\left(1.5^{\circ}, 2.0^{\circ}\right.$, and $\left.2.5^{\circ} \mathrm{C}\right)$ against the reference climate (1971-2000) based on all the five (PET-TH, PET-HS, PET-PM, PET-EN, and PET-MPM) methods using CMIP5 GCMs over South Asia (Figs. 5 and 6). As expected, PET-TH showed the largest increase $(15 \%-$ $35 \%$ ) under the warming climate (Fig. 5, Table S10).
In contrast, PET-EN and PET-MPM showed a smaller $(0.5 \%-5 \%)$ increase in the warming climate in CMIP5 GCMs (Fig. 5). At lower warming $\left(1.5^{\circ} \mathrm{C}\right)$, the projected change in PET-EN in CMIP5 GCMs is negative for the majority of South Asia (Fig. 5). Moreover, even at a higher warming level $\left(2.5^{\circ} \mathrm{C}\right)$, PET-EN is projected to increase by about $3 \%$ over South Asia (Fig. 5). Further, we estimated the ensemble mean 30-yr moving mean change (\%) in PET against the reference climate 19712000 for the period 2000-2100 based on CMIP5 using all the five PET methods (Fig. 6). PET-EN and PET-MPM method show the least increase at the end of the twentyfirst century, and PET-TH shows the highest increase in all the climatic regions. PET is projected to rise the most in the semiarid while the least in the humid region (Fig. 6). Since the CMIP5 simulations used in our study are based on a single initial condition, we used CESMLENS simulations based on 40 initial conditions to compare the PET projections. We find that PET projections from CESM-LENS are consistent with the CMIP5 for all the climatic regions (Fig. S13). However, as expected, the uncertainty ( \pm 1 standard deviation) in the PET projections from CESM-LENS is less than that of CMIP5 (Fig. S13). Overall, we show that the warming climate in South Asia will lead to increased atmospheric water demands (PET), which may vary with the climatic regions as well with the methods to estimate PET (Figs. 5 and 6, Fig. S13).

Milly and Dunne (2016) and Yang et al. (2019) reported that the difference in the PET projections is mainly due to the response of vegetation in the warming climate. Milly and Dunne (2016) argued that the change in PET in the future climate (2081-2100) is highly overestimated by PET-PM compared to the PET-EN. Ignoring the response of surface resistance (resistance of vapor flow through stomata openings) in the increased warming showed the overestimation of atmospheric water demand in PET-PM (Yang et al. 2019). Yang et al. (2019) reported that the changes in PET caused by the change in surface resistance are more than the change in net radiation, vapor pressure deficit, and wind in the PET-MPM method. Overall, our results consistent with the previous studies (Yang et al. 2019; Milly and Dunne 2016) and to avoid the overestimation in the PET under the warming climate, we need to either use PET-EN and PET-MPM methods or soil moisture for drought assessment.

\section{2) Projected changes in SeVere Drought FREQUENCY IN SOUTH ASIA}

We estimated the changes in the frequency (per decade) of severe (SPEI or SSI $<-1.2$ ) droughts based on the five PET estimates and soil moisture under the 

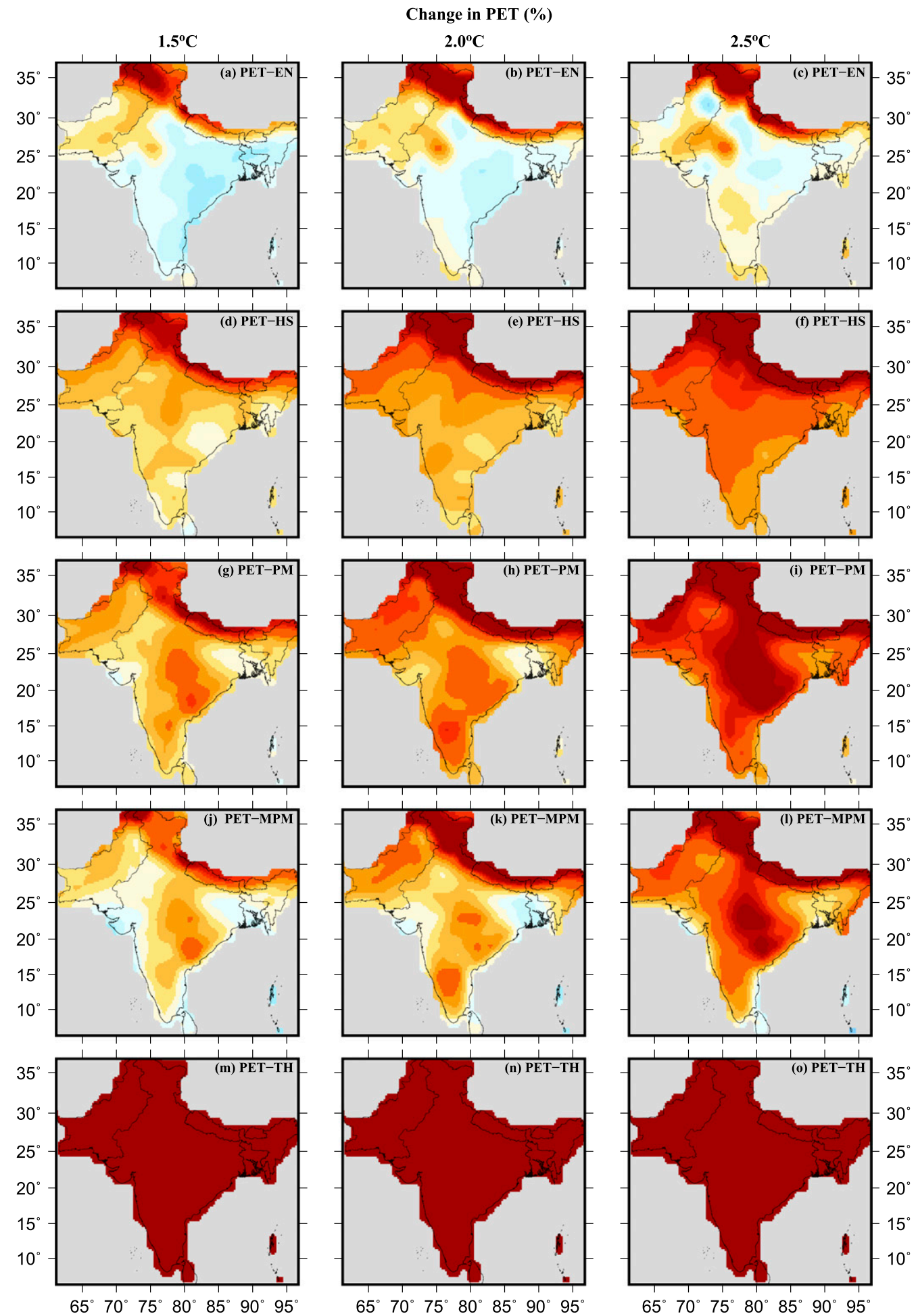

$\begin{array}{lllllllllll}-10 & -8 & -6 & -4 & -2 & 0 & 2 & 4 & 6 & 8 & 10(\%)\end{array}$

FIG. 5. Projected changes (\%) in annual mean PET using the CMIP5 GCMs for $1.5^{\circ}, 2.0^{\circ}$, and $2.5^{\circ} \mathrm{C}$ warming worlds (a)-(c) Ensemble mean projected changes in annual mean PET (\%) against the reference climate (19712000) based on PET-EN method in a $1.5^{\circ}, 2.0^{\circ}$, and $2.5^{\circ} \mathrm{C}$ warming world using the six CMIP5 GCMs. (d)-(o) As in (a)-(c), but for PET-HS in (d)-(f), PET-PM in (g)-(i), PET-MPM in (j)-(l), and PET-TH in (m)-(o). 

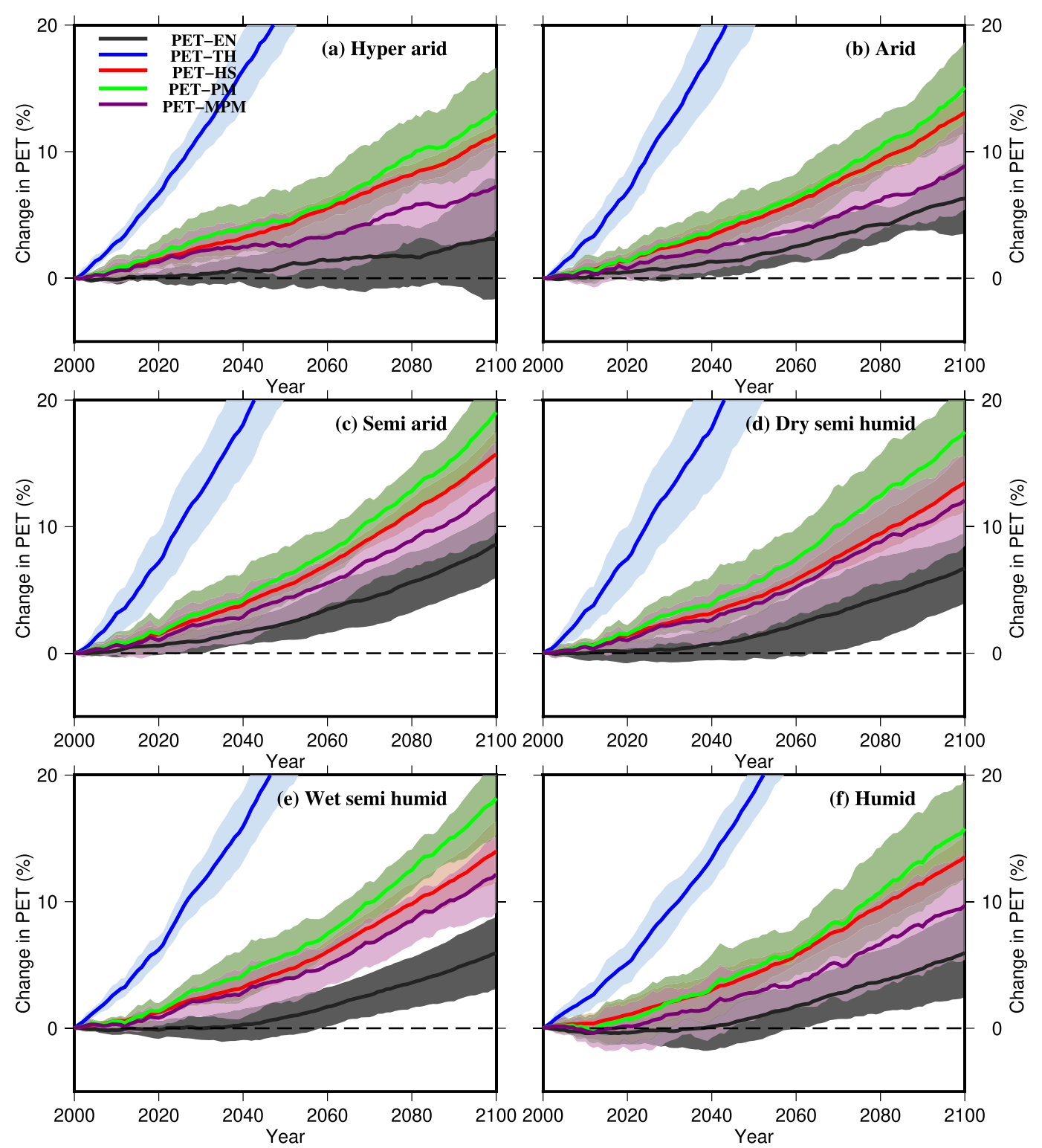

FIG. 6. Projected change (\%) in annual mean PET using CMIP5 GCMs for the period 2000-2100. (a) Ensemble mean 30-yr average change (\%) in annual mean PET against the reference climate (1971-2000) for the period 20002100 using six CMIP5 GCMs in the hyperarid region based on PET-EN (black), PET-TH (blue), PET-HS (red), PET-PM (green), and PET-MPM (purple). (b)-(f) As in (a), but for arid in (b), semiarid in (c), dry semihumid in (d), wet semihumid in (e), and humid in (f) regions. The shaded area shows the uncertainty ( \pm 1 standard deviation) in change (\%) in annual mean PET due to six different CMIP5 GCMs.

$1.5^{\circ}, 2.0^{\circ}$, and $2.5^{\circ} \mathrm{C}$ warming worlds (Fig. 7). Soil moisture represents storage based on actual evapotranspiration instead of PET. The projected frequency of severe droughts in PET-TH is significantly higher than the other PET over South Asia (Fig. 8, Table S11). For instance, PET-TH projects a rise in of 3-4 severe droughts per decade under $1.5^{\circ}$ and $2.0^{\circ} \mathrm{C}$ warming worlds in comparison to only about 1 severe drought per decade in PET-EN and PET-MPM (Fig. 7, Table S11). A rise in the global mean temperature to $1.5^{\circ} \mathrm{C}$ from the preindustrial level will result in a moderate increase in the frequency of severe droughts in a large part of South Asia in CMIP5 GCMs (Fig. 7). If the global mean temperature increases to $2.0^{\circ}$ or $2.5^{\circ} \mathrm{C}$ above the preindustrial level, a large part of Pakistan and western and central India are projected to experience an increase in the frequency of severe droughts in CMIP5 GCMs (Fig. 7). Drought projections based on SPEI-EN and 
Change in severe drought frequency
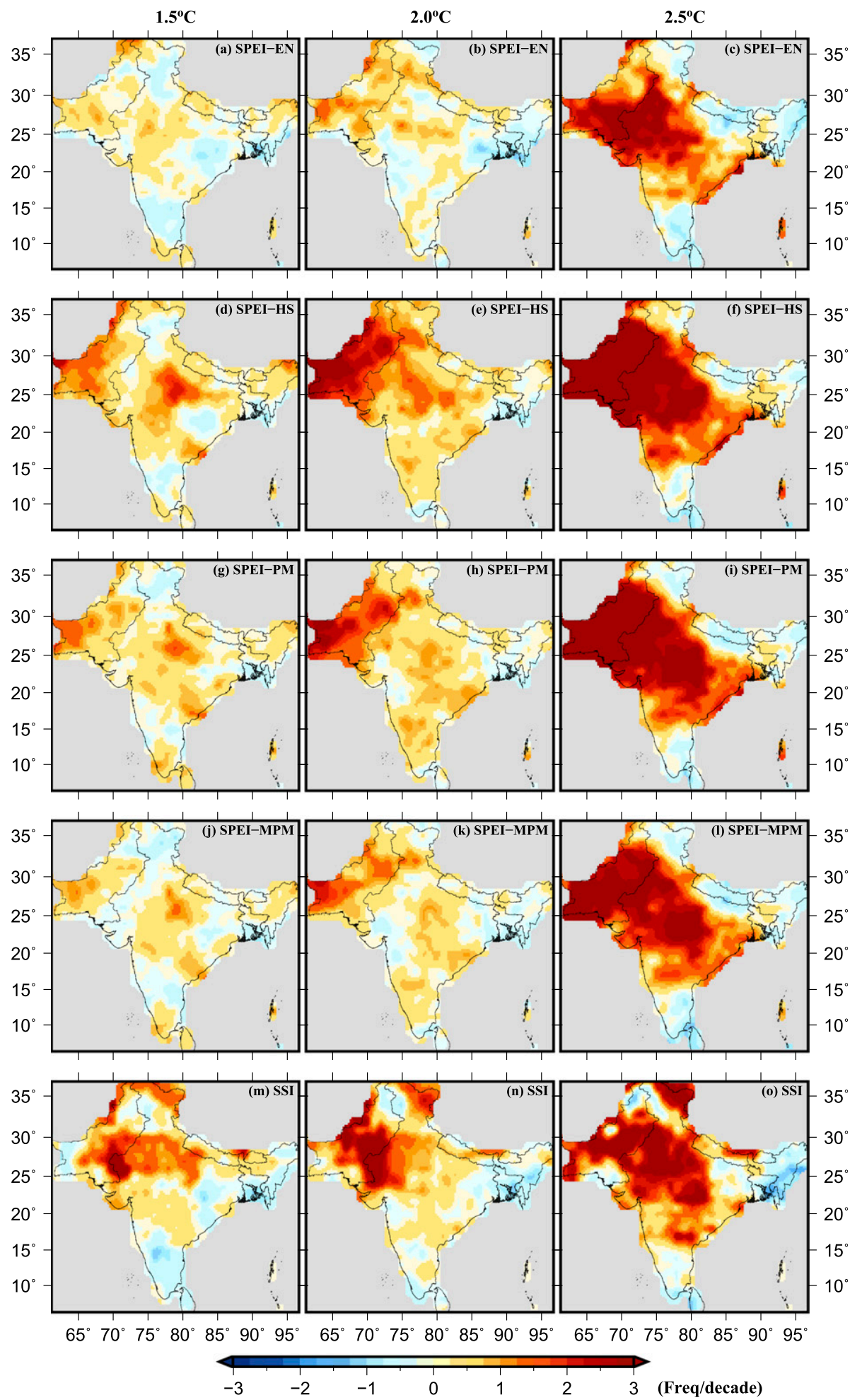

FIG. 7. Projected changes in the frequency of severe drought (SPEI or SSI $<-1.2$ ) per decade under $1.5^{\circ}, 2.0^{\circ}$, and $2.5^{\circ} \mathrm{C}$ warming worlds. (a)-(c) Ensemble mean projected changes in severe drought frequency (per decade) using 12-month SPEI at the end of December based on PET-EN in a $1.5^{\circ}, 2.0^{\circ}$, and $2.5^{\circ} \mathrm{C}$ warming world, respectively. Changes are estimated with respect to the reference climate (1971-2000) using the six CMIP5 GCMs. (d)-(o) As in (a)-(c), but for SPEI based on PET-HS in (d)-(f), PET-PM in (g)-(i), PET-MPM in (j)-(l), and SSI in (m)-(o). 

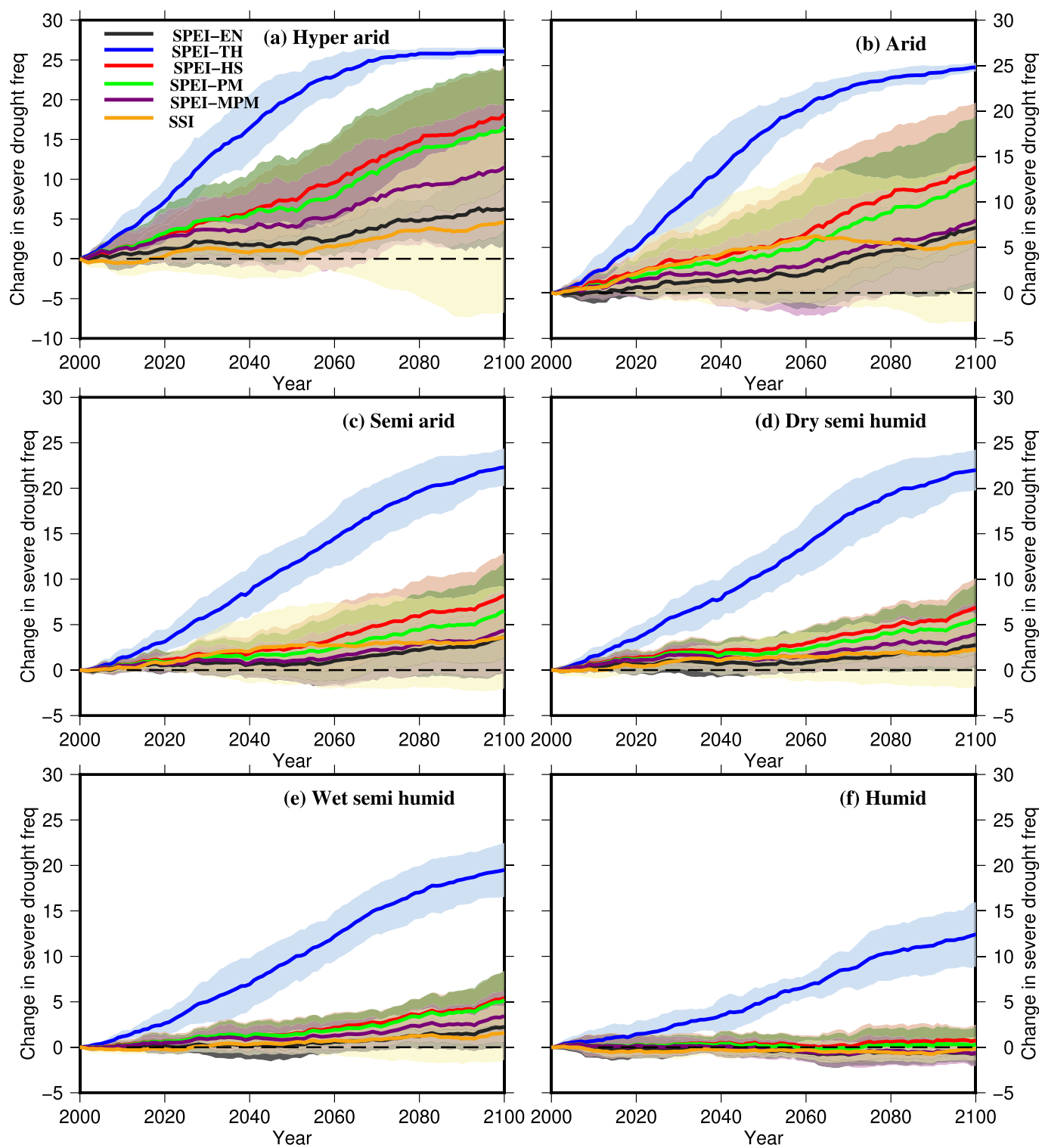

FIG. 8. Projected change in severe drought (SPEI or SSI <-1.2) frequency using CMIP5 GCMs for the period 2000-2100. (a) Ensemble mean 30-yr average change in severe drought frequency against the reference climate (1971-2000) for the period 2000-2100 using six CMIP5 GCMs in the hyperarid region based on SPEI-EN (black), SPEI-TH (blue), SPEI-HS (red), SPEI-PM (green), SPEI-MPM (purple), and SSI (yellow). (b)-(f) As in (a), but for arid in (b), semiarid in (c), dry semihumid in (d), wet semihumid in (e), and humid in (f) regions. The shaded area shows the uncertainty ( \pm 1 standard deviation) in the change in drought frequency due to six different CMIP5 GCMs.

SPEI-MPM show a higher frequency of severe drought compared to SSI under the warming climate (Fig. 7). This difference is mainly due to the high persistence of soil moisture (Mishra et al. 2018). In addition, based on the 30-yr moving mean change we find that drought frequency and area are projected to rise in the majority of climatic regions in South Asia (Fig. 8, Fig. S15). Results based on the CMIP5 GCMs and CESM-LENS simulations are consistent in terms of projected changes, however, differ for the uncertainty estimates under the warming climate (Fig. 8, Figs. S14-S16). Overall, we find that PET-EN- and PET-MPM-based drought estimates are comparable at higher projected warming $\left(2.5^{\circ} \mathrm{C}\right.$; Fig. 7$)$.

\section{3) UNCERTAINTY ASSESSMENT}

Finally, we estimated the contribution of models (CMIP5 GCMs), PET methods, and their interaction in total uncertainty in the PET estimates and drought frequency under the $1.5^{\circ}, 2.0^{\circ}$, and $2.5^{\circ} \mathrm{C}$ warming climate (Fig. 9). The contribution of PET methods in the 
(a) PET change

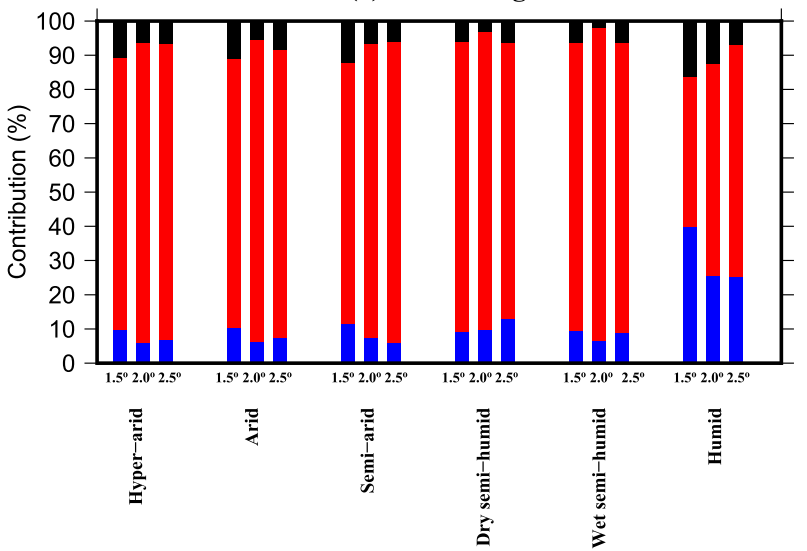

Interaction

(b) Drought freq change

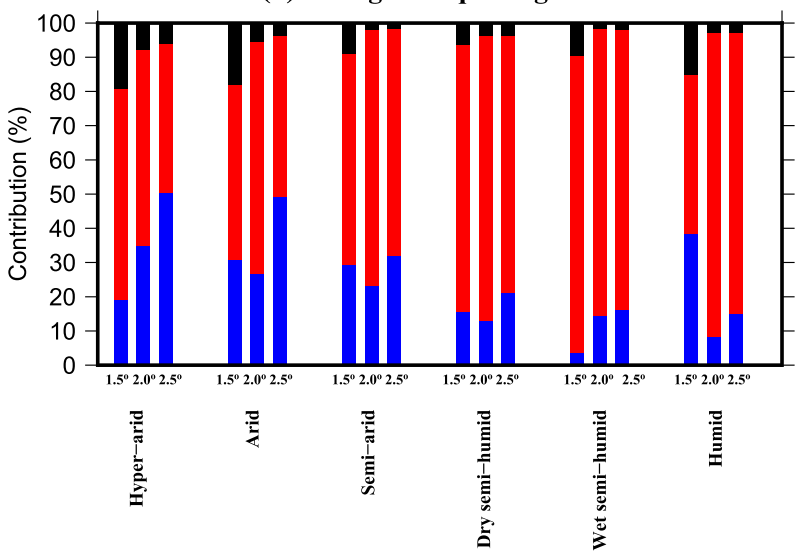

GCMs PET Methods (Four methods) Interaction

(c) PET change

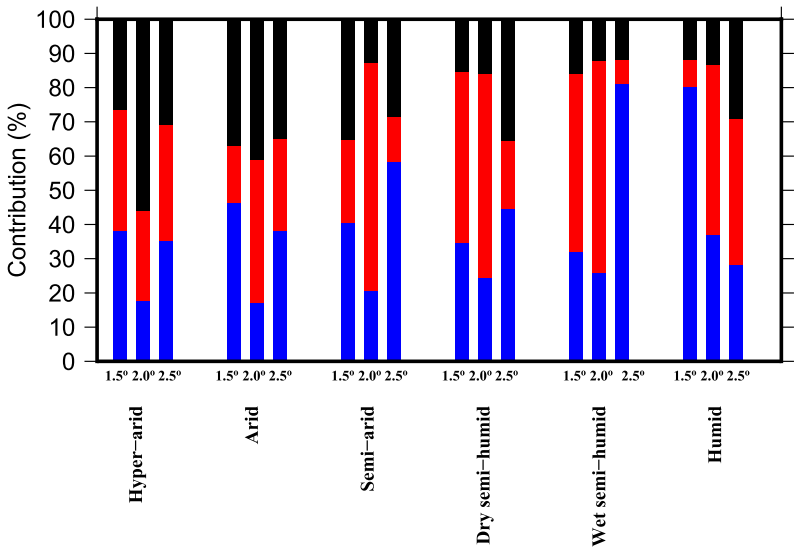

(d) Drought freq change

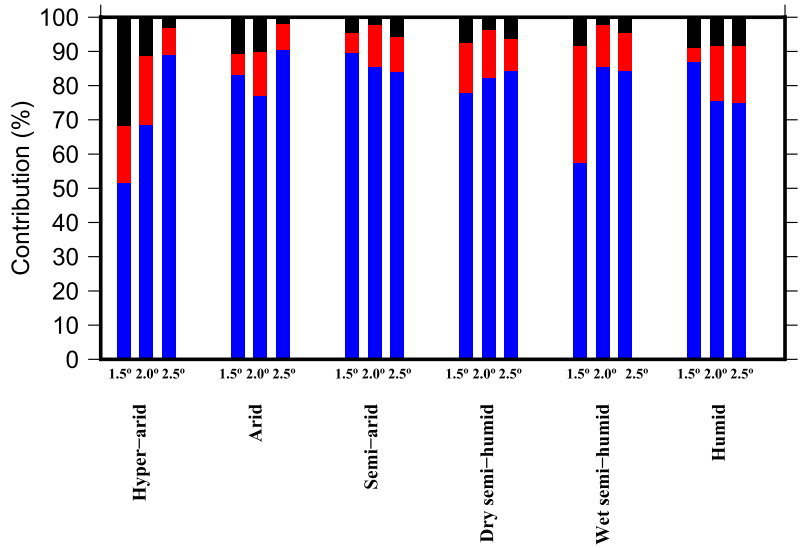

FIG. 9. Contribution (\%) in the overall uncertainty due to different PET methods, CMIP5 GCMs, and their interaction under $1.5^{\circ}, 2.0^{\circ}$, and $2.5^{\circ} \mathrm{C}$ warming using ANOVA method. (top) Contribution of the six CMIP5 GCMs (blue), five PET methods (red), and their interaction (black) in the overall uncertainty of (a) PET change and (b) drought frequency projections in hyperarid, arid, semiarid, dry semihumid, wet semihumid, and humid regions under $1.5^{\circ}, 2.0^{\circ}$, and $2.5^{\circ} \mathrm{C}$ warming worlds. (c), (d) As in (a) and (b), but using only four PET methods excluding PET-TH.

overall uncertainty is higher $(>70 \%)$ than the contribution from the CMIP5 GCMs, and their interaction for the majority of the climatic zones (Fig. 9a). This higher contribution of PET methods in total uncertainty is primarily due to PET-TH. Excluding PET-TH, the contribution from PET methods reduces to $30 \%-40 \%$ of total uncertainty, which is comparable to the contribution in uncertainty from CMIP5 GCMs (Fig. 9c). Similar to uncertainty assessment in PET projections, we estimated the contribution of PET methods, CMIP5 GCMs, and their interaction in the overall uncertainty in the projection of drought frequency (Figs. 9b,d). Since drought estimates also depend on precipitation, uncertainty in precipitation in CMIP5 GCMs contributes substantially to the overall uncertainty (Figs. S17 and S18).
Our results show that CMIP5 GCMS contribute 70\%$80 \%$ to the overall uncertainty in the frequency of drought projections under the warming climate. Therefore, the evaluation of CMIP5 GCMs for their ability to simulate summer monsoon is critical for drought projections in South Asia (Aadhar and Mishra 2019).

\section{Conclusions}

Based on our findings, the following conclusions can be made:

- South Asia experienced a significant ( $p$ value $<0.05$ ) warming during 1979-2018 with arise in temperature in all the climatic regions $\left(1.1^{\circ}-1.8^{\circ} \mathrm{C}\right)$. However, PET 
has slightly decreased in the majority of South Asia due to the decline in the vapor pressure deficit, wind speed, net radiation, and diurnal temperature range during the 1979-2018 period.

- PET estimates show a large uncertainty ( \pm 1 standard deviation) that varies in different climate regions of South Asia during the observed period (1979-2018). The observed increase in PET-TH in South Asia is significantly higher than the other four PET methods. The sensitivity of PET-TH to temperature is about 3 times higher than PET-HS, PET-PM, and PET-MPM for the majority of the climatic regions. The areal extent of severe droughts estimated using SPEI-EN and SPEIMPM compare well with the SSI based areal extent during the observed period. However, there are large differences in drought and PET estimates in extreme dry (hyperarid, arid) and wet (humid) regions.

- PET-EN and PET-MPM show that atmospheric water demand is projected to increase in CMIP5 GCMs under the $1.5^{\circ}, 2.0^{\circ}$, and $2.5^{\circ} \mathrm{C}$ warming worlds in South Asia. The CMIP5 GCMs and CESM-LENS simulations are consistent in terms of projected changes in PET over South Asia under the warming climate. The frequency of severe droughts based on CMIP5 GCMs (based on PET-EN and PET-MPM) is projected to rise by twofold in large part of Pakistan and western and central India (mostly drier regions) if the global mean temperature increases to $2.0^{\circ} \mathrm{C}$ or above from the preindustrial level. Moreover, drought estimates based on PET-EN and PET-MPM are consistent with soil moisture based drought estimates under the warming climate. PET methods contribute the most to the overall uncertainty in PET and drought projections under the warming climate in South Asia.

- Drought estimates based on PET-TH in the observed and projected future climate are not reliable in South Asia primarily due to the high sensitivity of PET-TH to temperature. Multiple methods of advanced PET estimates (PET-EN and PET-MPM) along with soil moisture can provide better estimates of drought projections under the warming climate. Uncertainty in CMIP5 projections to simulate summer monsoon precipitation can be a key source of the uncertainty in drought projections in South Asia. Therefore, CMIP5 GCMs should be carefully evaluated for the key monsoon features before the assessment for the future climate.

Acknowledgments. The first author appreciates financial assistance from the Indian Ministry of Human Resource Development (MHRD). The study is partially funded by the ITRA-Water and BELMONT forum projects. We also appreciate the data support from ECMWF-ERA5 (https://cds.climate.copernicus.eu/ \#!/search?text=ERA5\&type $=$ dataset) and CMIP5 (https:// esgf-node.llnl.gov/search/cmip5/).

\section{REFERENCES}

Aadhar, S., and V. Mishra, 2017: High-resolution near real-time drought monitoring in South Asia. Sci. Data, 4, 170145, https:// doi.org/10.1038/sdata.2017.145.

— affected by dryness in South Asia under $1.5^{\circ} \mathrm{C}, 2.0^{\circ} \mathrm{C}$ and $2.5^{\circ} \mathrm{C}$ warmer worlds. Environ. Res. Lett., 14, 114021, https://doi.org/ 10.1088/1748-9326/ab4862.

Armstrong, R. A., S. V. Slade, and F. Eperjesi, 2000: An introduction to analysis of variance (ANOVA) with special reference to data from clinical experiments in optometry. Ophthalmic Physiol. Opt., 20, 235-241, https://doi.org/ 10.1046/j.1475-1313.2000.00502.x.

Arora, V. K., 2002: The use of the aridity index to assess climate change effect on annual runoff. J. Hydrol., 265, 164-177, https://doi.org/10.1016/S0022-1694(02)00101-4.

Ashfaq, M., D. Rastogi, R. Mei, D. Touma, and L. R. Leung, 2017: Sources of errors in the simulation of south Asian summer monsoon in the CMIP5 GCMs. Climate Dyn., 49, 193-223, https://doi.org/10.1007/s00382-016-3337-7.

Bandyopadhyay, A., A. Bhadra, N. S. Raghuwanshi, and R. Singh, 2009: Temporal trends in estimates of reference evapotranspiration over India. J. Hydrol. Eng., 14, 508-515, https:// doi.org/10.1061/(ASCE)HE.1943-5584.0000006.

Chattopadhyay, N., and M. Hulme, 1997: Evaporation and potential evapotranspiration in India under conditions of recent and future climate change. Agric. For. Meteor., 87, 55-73, https:// doi.org/10.1016/S0168-1923(97)00006-3.

Dai, A., 2013: Increasing drought under global warming in observations and models. Nat. Climate Change, 3, 52-58, https:// doi.org/10.1038/nclimate1633.

Dewes, C. F., I. Rangwala, J. J. Barsugli, M. T. Hobbins, and S. Kumar, 2017: Drought risk assessment under climate change is sensitive to methodological choices for the estimation of evaporative demand. PLoS One, 12, e0174045, https:// doi.org/10.1371/journal.pone.0174045.

Dey, N., M. Alam, A. Sajjan, M. Bhuiyan, L. Ghose, Y. Ibaraki, and F. Karim, 2011: Assessing environmental and health impact of drought in the northwest Bangladesh. J. Environ. Sci. Nat. Resour., 4, 89-97, https://doi.org/10.3329/jesnr.v4i2.10141.

Fu, Q., and S. Feng, 2014: Responses of terrestrial aridity to global warming. J. Geophys. Res. Atmos., 119, 7863-7875, https:// doi.org/10.1002/2014JD021608.

Guhathakurta, P., and M. Rajeevan, 2008: Trends in the rainfall pattern over India. Int. J. Climatol., 28, 1453-1469, https:// doi.org/10.1002/joc.1640.

Gupta, V., and M. K. Jain, 2018: Investigation of multi-model spatiotemporal mesoscale drought projections over India under climate change scenario. J. Hydrol., 567, 489-509, https:// doi.org/10.1016/j.jhydrol.2018.10.012.

Hao, Z., and A. Aghakouchak, 2013: Multivariate standardized drought index: A parametric multi-index model. Adv. Water Resour., 57, 12-18, https://doi.org/10.1016/j.advwatres.2013.03.009.

Hargreaves, G. H., and Z. A. Samani, 1985: Reference crop evapotranspiration from temperature. Appl. Eng. Agric., 1, 96-99, https://doi.org/10.13031/2013.26773. 
Jaswal, A. K., G. S. P. Rao, and U. S. De, 2008: Spatial and temporal characteristics of evaporation trends over India during 1971-2000. Mausam, 59, 149.

Kay, J. E., and Coauthors, 2015: The Community Earth System model (CESM) large ensemble project: A community resource for studying climate change in the presence of internal climate variability. Bull. Amer. Meteor. Soc., 96, 1333-1349, https://doi.org/10.1175/BAMS-D-13-00255.1.

Kendall, M. G., 1975: Rank Correlation Methods. 4th ed. Charles Griffin, 202 pp.

King, A. D., D. J. Karoly, and B. J. Henley, 2017: Australian climate extremes at $1.5^{\circ} \mathrm{C}$ and $2^{\circ} \mathrm{C}$ of global warming. Nat. Climate Change, 7, 412-416, https://doi.org/10.1038/nclimate3296.

Knutti, R., and J. Sedláček, 2013: Robustness and uncertainties in the new CMIP5 climate model projections. Nat. Climate Change, 3, 369-373, https://doi.org/10.1038/nclimate1716.

Kumar, K. N., M. Rajeevan, D. S. Pai, A. K. Srivastava, and B. Preethi, 2013: On the observed variability of monsoon droughts over India. Wea. Climate Extreme, 1, 42-50, https:// doi.org/10.1016/j.wace.2013.07.006.

Kumar, S., J. L. Kinter, Z. Pan, and J. Sheffield, 2016: Twentieth century temperature trends in CMIP3, CMIP5, and CESM-LE climate simulations: Spatial-temporal uncertainties, differences, and their potential sources. J. Geophys. Res. Atmos. 121, 9561-9575, https://doi.org/10.1002/2015JD024382.

Lehner, F., S. Coats, T. F. Stocker, A. G. Pendergrass, B. M Sanderson, C. C. Raible, and J. E. Smerdon, 2017: Projected drought risk in $1.5^{\circ} \mathrm{C}$ and $2^{\circ} \mathrm{C}$ warmer climates. Geophys. Res. Lett., 44, 7419-7428, https://doi.org/10.1002/2017GL074117.

Liu, W., F. Sun, W. Ho Lim, J. Zhang, H. Wang, H. Shiogama, and Y. Zhang, 2018: Global drought and severe drought-Affected populations in 1.5 and $2^{\circ} \mathrm{C}$ warmer worlds. Earth Syst. Dyn., 9, 267-283, https://doi.org/10.5194/esd-9-267-2018.

Mahto, S. S., and V. Mishra, 2019: Does ERA-5 outperform other reanalysis products for hydrologic applications in India? J. Geophys. Res. Atmos., 124, 9423-9441, https://doi.org/ 10.1029/2019JD031155.

Mann, H. B., 1945: Nonparametric tests against trend. Econometrica, 13, 245-259, https://doi.org/10.2307/1907187.

McKenney, M. S., and N. J. Rosenberg, 1993: Sensitivity of some potential evapotranspiration estimation methods to climate change. Agric. For. Meteor., 64, 81-110, https://doi.org/10.1016/ 0168-1923(93)90095-Y.

Middleton, N., and D. Thomas, 1997: World Atlas of Desertification. 2nd ed. Arnold, 182 pp.

Milly, P. C. D., and K. A. Dunne, 2016: Potential evapotranspiration and continental drying. Nat. Climate Change, 6, 946-949, https://doi.org/10.1038/nclimate3046.

Mishra, V., S., Aadhar, A. Asoka, S. Pai, and R. Kumar, 2016: On the frequency of the 2015 monsoon season drought in the Indo-Gangetic Plain. Geophys. Res. Lett., 43, 12 102-12112, https://doi.org/10.1002/2016GL071407.

_ B. V. Smoliak, D. P. Lettenmaier, and J. M. Wallace, 2012: A prominent pattern of year-to-year variability in Indian summer monsoon rainfall. Proc. Natl. Acad. Sci. USA, 109, 72137217, https://doi.org/10.1073/pnas.1119150109.

- R. Kumar, H. L. Shah, L. Samaniego, S. Eisner, and T. Yang, 2017: Multimodel assessment of sensitivity and uncertainty of evapotranspiration and a proxy for available water resources under climate change. Climatic Change, 141, 451-465, https:// doi.org/10.1007/s10584-016-1886-8.

, R. Shah, S. Azhar, H. Shah, P. Modi, and R. Kumar, 2018: Reconstruction of droughts in India using multiple land-surface models (1951-2015). Hydrol. Earth Syst. Sci., 22, 2269-2284, https://doi.org/10.5194/hess-22-2269-2018.

Monteith, J. L., 1965: Evaporation and environment. Symp. Soc. Exp. Biol., 19, 205-234.

Novick, K. A., and Coauthors, 2016: The increasing importance of atmospheric demand for ecosystem water and carbon fluxes. Nat. Climate Change, 6, 1023-1027, https://doi.org/10.1038/ nclimate3114.

Penman, H. L., 1948: Natural evaporation from open water, bare soil and grass. Proc. Roy. Soc. London, 193, 120-145, https:// doi.org/10.1098/rspa.1948.0037.

Ponce, V. M., R. P. Pandey, and S. Ercan, 2000: Characterization of drought across climatic spectrum. J. Hydrol. Eng., 5, 222-224, https://doi.org/10.1061/(ASCE)1084-0699(2000)5:2(222).

Prudhomme, C., and Coauthors, 2014: Hydrological droughts in the 21st century, hotspots and uncertainties from a global multimodel ensemble experiment. Proc. Natl. Acad. Sci. USA, 111, 3262-3267, https://doi.org/10.1073/pnas.1222473110.

Raftery, A. E., A. Zimmer, D. M. W. Frierson, R. Startz, and P. Liu, 2017: Less than $2^{\circ} \mathrm{C}$ warming by 2100 unlikely. Nat. Climate Change, 7, 637-641, https://doi.org/10.1038/nclimate3352.

Ramarao, M. V. S., J. Sanjay, R. Krishnan, M. Mujumdar, A. Bazaz, and A. Revi, 2019: On observed aridity changes over the semiarid regions of India in a warming climate. Theor. Appl. Climatol., 136, 693-702, https://doi.org/10.1007/s00704018-2513-6.

Ray, J. D., R. W. Gesch, T. R. Sinclair, and L. Hartwell Allen, 2002: The effect of vapor pressure deficit on maize transpiration response to a drying soil. Plant Soil, 239, 113-121, https:// doi.org/10.1023/A:1014947422468.

Rhee, J., and J. Cho, 2016: Future changes in drought characteristics: Regional analysis for South Korea under CMIP5 projections. J. Hydrometeor., 17, 437-451, https://doi.org/10.1175/ JHM-D-15-0027.1.

Roderick, M. L., P. Greve, and G. D. Farquhar, 2015: On the assessment of aridity with changes in atmospheric $\mathrm{CO}_{2}$. Water Resour. Res., 51, 5450-5463, https://doi.org/10.1002/ 2015WR017031.

Roxy, M. K., K. Ritika, P. Terray, R. Murtugudde, K. Ashok, and B. N. Goswami, 2015: Drying of Indian subcontinent by rapid Indian Ocean warming and a weakening land-sea thermal gradient. Nat. Commun., 6, 7423, https://doi.org/10.1038/ ncomms 8423

Safriel, U., and Coauthors, 2005: Dryland systems. Current State and Trends, Vol. 1, Ecosystems and Human Well-Being, R. Hassan et al., Eds., Millennium Ecosystem Assessment Series, World Resources Institute, 623-662.

Scheff, J., and D. M. W. Frierson, 2014: Scaling potential evapotranspiration with greenhouse warming. J. Climate, 27, 15391558, https://doi.org/10.1175/JCLI-D-13-00233.1.

Sen, P. K., 1968: Estimates of the regression coefficient based on Kendall's Tau. J. Amer. Stat. Assoc., 63, 1379-1389, https:// doi.org/10.1080/01621459.1968.10480934.

Sheffield, J., E. F. Wood, and M. L. Roderick, 2012: Little change in global drought over the past 60 years. Nature, 491, 435-438, https://doi.org/10.1038/nature11575.

Singh, D., M. Tsiang, B. Rajaratnam, and N. S. Di, 2014: Observed changes in extreme wet and dry spells during the South Asian summer monsoon season. Nat. Climate Change, 4, 456-461, https://doi.org/10.1038/nclimate2208.

Sinha, A., G. Kathayat, H. Cheng, S. F. M. Breitenbach, M. Berkelhammer, M. Mudelsee, J. Biswas, and R. L. Edwards, 2015: Trends and oscillations in the Indian summer 
monsoon rainfall over the last two millennia. Nat. Commun., 6, 6309, https://doi.org/10.1038/ncomms7309.

Svoboda, M., and Coauthors, 2002: The Drought Monitor. Bull. Amer. Meteor. Soc., 83, 1181-1190, https://doi.org/10.1175/ 1520-0477-83.8.1181.

Swann, A. L. S., F. M. Hoffman, C. D. Koven, and J. T. Randerson, 2016: Plant responses to increasing $\mathrm{CO}_{2}$ reduce estimates of climate impacts on drought severity. Proc. Natl. Acad. Sci. USA, 113, 10 019-10 024, https://doi.org/10.1073/pnas.1604581113.

Taylor, K. E., R. J. Stouffer, and G. A. Meehl, 2012: An overview of CMIP5 and the experiment design. Bull. Amer. Meteor. Soc., 93, 485-498, https://doi.org/10.1175/BAMS-D-11-00094.1.

Thornthwaite, C. W., 1948: An approach toward a rational classification of climate. Geogr. Rev., 38, 55, https://doi.org/10.2307/210739.

Touma, D., M. Ashfaq, M. A. Nayak, S. C. Kao, and N. S. Diffenbaugh, 2015: A multi-model and multi-index evaluation of drought characteristics in the 21st century. J. Hydrol., 526, 196-207, https://doi.org/10.1016/j.jhydrol.2014.12.011.

Trenberth, K. E., A. Dai, G. van der Schrier, P. D. Jones, J. Barichivich, K. R. Briffa, and J. Sheffield, 2014: Global warming and changes in drought. Nat. Climate Change, 4, 1722, https://doi.org/10.1038/nclimate2067.

Valiantzas, J. D., 2018: Modification of the Hargreaves-Samani model for estimating solar radiation from temperature and humidity data. J. Irrig. Drain. Eng., 144, 06017014, https:// doi.org/10.1061/(ASCE)IR.1943-4774.0001275.

Vano, J. A., T. Das, D. P. Lettenmaier, J. A. Vano, T. Das, and D. P. Lettenmaier, 2012: Hydrologic sensitivities of Colorado river runoff to changes in precipitation and temperature. J. Hydrometeor., 13, 932-949, https://doi.org/10.1175/JHM-D-11-069.1.
Vautard, R., J. Cattiaux, P. Yiou, J. N. Thépaut, and P. Ciais, 2010: Northern Hemisphere atmospheric stilling partly attributed to an increase in surface roughness. Nat. Geosci., 3, 756-761, https://doi.org/10.1038/ngeo979.

Vetter, T., S. Huang, V. Aich, T. Yang, X. Wang, V. Krysanova, and F. Hattermann, 2015: Multi-model climate impact assessment and intercomparison for three large-scale river basins on three continents. Earth Syst. Dyn., 6, 17-43, https:// doi.org/10.5194/esd-6-17-2015.

Vicente-Serrano, S. M., S. Beguería, and J. I. López-Moreno, 2010: A multiscalar drought index sensitive to global warming: The standardized precipitation evapotranspiration index. J. Climate, 23, 1696-1718, https://doi.org/10.1175/2009JCLI2909.1.

Yang, Y., M. L. Roderick, S. Zhang, T. R. McVicar, and R. J. Donohue, 2019: Hydrologic implications of vegetation response to elevated $\mathrm{CO}_{2}$ in climate projections. Nat. Climate Change, 9, 44-48, https://doi.org/10.1038/s41558-018-0361-0.

Yuan, S., and S. M. Quiring, 2014: Drought in the U.S. Great Plains (1980-2012): A sensitivity study using different methods for estimating potential evapotranspiration in the Palmer drought severity index. J. Geophys. Res. Atmos., 119, 10 996-11010, https://doi.org/10.1002/2014JD021970.

Yue, S., and C. Y. Wang, 2002: Applicability of prewhitening to eliminate the influence of serial correlation on the MannKendall test. Water Resour. Res., 38, 1068, https://doi.org/ 10.1029/2001WR000861.

Zhao, T., and A. Dai, 2015: The magnitude and causes of global drought changes in the twenty-first century under a lowmoderate emissions scenario. J. Climate, 28, 4490-4512, https://doi.org/10.1175/JCLI-D-14-00363.1. 